\title{
First Report on Isolation of Salmonella Enteritidis from Eggs at Grocery Stores in Korea
}

\author{
Young Jo Kim¹, Bo Ra Song ${ }^{1}$, Jong Su Lim², Eun Jeong Heo ${ }^{1}$, Hyun Jung Park ${ }^{1}$, Sung Hwan Wee, \\ Soon Min $\mathrm{Oh}^{3}$, and Jin San Moon* \\ Veterinary Pharmaceutical Management Division, Animal and Plant Quarantine Agency, Anyang 430-757, Korea \\ ${ }^{1}$ Livestock Product Standard Division, Food Microbiology Division, and Agro-Livestock \& Fishery Products \\ Policy Division, Ministry of Food and Drug Safety, Cheongwon 363-951, Korea \\ ${ }^{2}$ College of Veterinary Medicine, Konkuk University, Seoul 143-701, Korea \\ ${ }^{3}$ Quarantine Policy Division, Ministry of Agriculture, Food and Rural Affairs, Sejong 339-012, Korea
}

\begin{abstract}
Salmonella Enteritidis is responsible for causing foodborne diseases upon consumption of egg products. While cases of $S$. Enteritidis isolation from eggs have been reported in other countries, no such cases have previously been reported in Korea. In this study, we report the first isolation and identification of $S$. Enteritidis from domestically distributed eggs in Korea. Eggs were collected from eight countrywide grocery stores during different seasons between 2011 and 2012. Egg contents and washing solution of egg shells were incubated in buffered peptone water, and the enriched broth was further enriched in tetrathionate broth and Rappaport-Vassiliadis. The secondary enriched broth was streaked on xylose lysine desoxycholate agar. The suspected colonies were confirmed to $S$. Enteritidis by a biochemical test, serotyping, and PCR test. Genetic relatedness among the isolates was analyzed using Diversilab Salmonella kit. Three strains of $S$. Enteritidis were isolated from egg contents and egg shells collected from grocery stores of the Eumseong-city in the fall of 2011. All three stains showed resistance to chloramphenicol, streptomycin, nalidixic acid, and ampicillin by the disk diffusion method. In addition, the isolates showed more than $99 \%$ DNA homology, indicating that they were presumably identical strains. Therefore, there is a requirement to monitor and control against $S$. Enteritidis from eggs in Korea.
\end{abstract}

Key words: egg, Salmonella Enteritidis, isolation, antibiotic resistance

\section{Introduction}

Food poisoning caused by Salmonella is an important source of foodborne disease worldwide. In particular, food poisoning by Salmonella upon consumption of eggs and egg products occurs annually in the United States, the Netherland, Canada, Germany, and other countries, thereby posing a risk to public health (Amedo et al., 1998; Henzler et al., 1998; Humphrey et al., 1989; Lee et al., 2002; Rowe, 1989; Wilson et al., 1998). In Korea, eggs are considered as an ideal food product and they contain various nutrients, including protein; thus, they are an integral part of a healthy and nutritious diet. Because of a greater availability of less expensive and functional eggs, more eggs are being consumed and there is an increased concern

*Corresponding author: Jin San Moon, Veterinary Pharmaceutical Management Division, Animl and Plant Quarantine Agency, Anyang 430-757, Korea. Tel: 82-31-467-4303, Fax: 82-31-4674321, E-mail: moonjs727@korea.kr regarding food poisoning by Salmonella (Chun, 2009; Jones et al., 1995; Lee et al., 2002; Stadelman, 1995).

In the United States, Salmonella spp. infection was reported in one of 10,000 eggs, and Salmonella spp. infection was identified in one of 15,000 eggs in the United Kingdom (Duguid and North, 1991). In the United Kingdom, where an average person eats three raw eggs per week, 1 in 100 people was found to be infected with Salmonella and suffer from food poisoning every year (Duguid and North, 1991). Because $S$. Enteritidis is specifically responsible among all other Salmonella species for food poisoning by consumption of eggs (Cowden et al., 1989; Coyle et al., 1988; Lin et al., 1988), standards have been established internationally to control the spread of $S$. Enteritidis by eggs (Codex, 1976, FDA, 2000).

In Korea, regular tests are annually conducted at eggs from farms to detect $S$. Enteritidis (MIFAFF Notice 2009169). In countries other than Korea, including the United States, cases of $S$. Enteritidis isolation have been reported (Baker, 1980; Humphrey et al., 1989); however, between 
2000 and 2011, no such cases have been reported either eggs from farms or distributed stage in Korea (Chun, 2009; Lee et al., 2002; Woo, 2005). In contrast, $S$. Enteritidis has been recently found more frequently from domestically slaughtered chickens (Lee et al., 2007), In addition the demands for eggs that are safe to consume are increasing with an increase in the annual production of eggs. In this study, therefore, eggs were collected during each season from eight countrywide grocery stores and subjected to regular testing to determine the $S$. Enteritidis infection ratio in domestically distributed eggs.

\section{Materials and Methods}

For isolating Salmonella from eggs, 20 eggs were pooled according to the FDA Bacteriological Analytical Manual (BAM) (BAM, 1998), and the Salmonella test was conducted according to the processing standards and ingredient specifications for livestock products (QIA Notice 2012162).

From fall, winter in 2011 to spring, summer in 2012, 100 eggs each were collected from four grocery stores in Gyeonggi Province (Hwasung-city, Icheon-city, Anseongcity, and Pocheon-city) and four stores in Eumseong-city in Chungbuk Province, Gunsan-city in Jeonbuk Province, Gumi-city in Gyeongbuk Provice, and Yangsan-city in Gyeongnam Provice, respectively.

Salmonella isolation tests were conducted five times with 20 eggs each time, corresponding to a total of 100 eggs. Sterilized saline solution was used to wash the egg shells of all 20 eggs, and the contents of all disinfected eggs were placed in a sterilized pack and agitated, before being enriched in buffered peptone water (BD, USA). The enriched broth was further enriched in tetrathionate (TT) broth (BD) and Rappaport-Vassiliadis (RV) broth (Merk, Germany). The secondary enriched broth was streaked on xylose lysine desoxycholate (XLD) agar (BD), and suspected colonies were transferred to triple sugar iron (TSI) agar (BD). Biochemical testing was conducted using an automated microbiological identification system (Vitek II ${ }^{\circledR}$, Biomeriux, France) to identify Salmonella spp.

For serotyping of the isolation strain, Edwards and Ewing's identification of Enterobacteriaceae procedure (Ewing, 1986) was used. Somatic (O) antigen was confirmed by slide agglutination test, which was performed using commercial antiserum (BD). Flagella antigen was inoculated into GI motility agar (BD) to activate the flagella, after which, it was inoculated into veal infusion broth (BD), cultured overnight, fixed with $0.6 \%$ formalin, and checked using tube agglutination test. The serotyped strain was checked again for $S$. Enteritidis by PCR (Soumet et al., 1999). Salmonella spp. was checked using ST11(5'-GCCAACCA TT GCTAAATTGGCGCA-3') a ST15(5'-GGTAGAAATTCCCAGCGGGTACTGG-3') primers (429 bp), and $S$. Enteritidis was checked using S1(5'GCCGTACACGAGCTTATAGA-3') \& S4(5'-ACCTACA GGGGCACAATAAC-3') primers (250 bp), respectively.

Rep-PCR typing was conducted to verify the genetic relationship between the isolates. DNA was extracted using an Ultra-Clean Microbial DNA Isolation kit (MoBio Laboratories, Canada) and amplified using a Diversilab kit (bioMerieux) along with positive and negative control DNA. Genetic homology was analyzed for each sample by locating and analyzing the intensity of DNA bands by Rep-software (bioMerieux) and Pearson's correlation method.

Antibiotic resistance testing was conducted using the disk diffusion method. Bacterial concentration was adjusted to McFarland No. 0.5 and applied to Muller-Hinton agar (BD) using a sterilized swab; antibiotic discs were subsequently inoculated using a dispenser (BD). Fifteen antibiotics were tested and resistance was judged as per the guidelines of Clinical and Laboratory Standards Institute (CLSI, 2012).

\section{Results and Discussion}

Of the eggs collected from the eight countrywide regions in spring, summer, fall, and winter, two strains of Salmonella from the egg shells and one strain from egg contents collected from the Eumseong-city region in the fall in 2011 were identified to $S$. Enteritidis by serological test (Table 1). In addition, we confirmed by PCR that all isolates were $S$. Enteritidis (Fig. 1). Based on the antibiotic resistance test, all three stains showed resistance to chloramphenicol, streptomycin, nalidixic acid, and ampicillin (Table 2). Upon analyzing the genetic relationship, three stains showed more than $99 \%$ homology, indicating that they were identical strains (Fig. 2).

S. gallinarum (Woo, 2005) has been previously found from domestically distributed eggs, and $S$. Enteritidis has been isolated from chicken, pork, and duck (Cho et al., 2011; Choi et al., 2008; Lee et al., 2007). However, this is the first study to report the isolation of $S$. Enteritidis from egg shells and egg contents of eggs distributed at grocery stores in Korea. $S$. Typhimurium, $S$. Agona, and $S$. Enteritidis have already been isolated from egg shells 
Table 1. Isolation of $S$. Enteritidis from eggs collected from grocery stores between 2011 and 2012 in Korea

\begin{tabular}{|c|c|c|c|c|c|c|c|c|}
\hline \multirow{3}{*}{$\begin{array}{l}\text { Grocery stores of } \\
\text { sample collection }\end{array}$} & \multicolumn{8}{|c|}{ Isolation of $S$. Enteritidis } \\
\hline & \multicolumn{2}{|c|}{ Spring } & \multicolumn{2}{|c|}{ Summer } & \multicolumn{2}{|c|}{ Fall } & \multicolumn{2}{|c|}{ Winter } \\
\hline & Egg shell & Content & Egg shell & Content & Egg shell & Content & Egg shell & Content \\
\hline Pocheon-city & - & - & - & - & - & - & - & - \\
\hline Hwasung-city & - & - & - & - & - & - & - & - \\
\hline Anseong-city & - & - & - & - & - & - & - & - \\
\hline Icheon-city & - & - & - & - & - & - & - & - \\
\hline Eumseong-city & - & & - & - & + & + & - & - \\
\hline Gunsan-city & - & - & - & - & - & - & - & - \\
\hline Gumi-city & - & - & - & - & - & - & - & - \\
\hline Yangsan-city & - & - & - & - & - & - & - & - \\
\hline
\end{tabular}

${ }^{*}$ Tests for $S$. Enteritidis were conducted five times with pooled egg contents and washing solution of egg shells of 20 eggs per grocery store.

Table 2. Antibiotic resistance of $S$. Enteritidis isolated from eggs in Korea

\begin{tabular}{|c|c|c|c|c|c|}
\hline \multicolumn{2}{|c|}{ Antibiotics } & \multicolumn{3}{|c|}{ S. Enteritidis isolates } & \multirow{2}{*}{$\begin{array}{c}\text { Reference } \\
\text { ATCC25922 }\end{array}$} \\
\hline Classification & Names & Egg $1^{1)}$ & $\operatorname{Egg} 2^{2)}$ & Egg $3^{1)}$ & \\
\hline \multirow{3}{*}{ Aminoglycosides } & Gentamicin & $\mathrm{S}^{3)}$ & $\mathrm{S}$ & $\mathrm{S}$ & $\mathrm{S}$ \\
\hline & Streptomycin & $\mathrm{R}^{4)}$ & $\mathrm{R}$ & $\mathrm{R}$ & $\mathrm{S}$ \\
\hline & Neomycin & S & $\mathrm{S}$ & $\mathrm{S}$ & $\mathrm{S}$ \\
\hline Aminopenicillin & Ampicillin & $\mathrm{R}$ & $\mathrm{R}$ & $\mathrm{R}$ & $\mathrm{S}$ \\
\hline $\begin{array}{l}\beta \text {-lactam / } \beta \text {-lactamase } \\
\text { inhibitor combinations }\end{array}$ & Amoxicillin / clavulanic acid & $\mathrm{S}$ & $\mathrm{S}$ & $\mathrm{S}$ & $\mathrm{S}$ \\
\hline Cephalosporin I & Cephalothin & $\mathrm{S}$ & $\mathrm{S}$ & $\mathrm{S}$ & $\mathrm{S}$ \\
\hline Cephamycin & Cefoxitin & $\mathrm{S}$ & $\mathrm{S}$ & $\mathrm{S}$ & $\mathrm{S}$ \\
\hline Cephalosporin III & Ceftiofur & $\mathrm{S}$ & $\mathrm{S}$ & $\mathrm{S}$ & $\mathrm{S}$ \\
\hline Fluoroquinolone & Ciprofloxacin & $\mathrm{S}$ & $\mathrm{S}$ & $\mathrm{S}$ & $\mathrm{S}$ \\
\hline Folate pathway inhibitors & Trimethoprim / Sulfamethoxazole & $\mathrm{S}$ & $\mathrm{S}$ & $\mathrm{S}$ & $\mathrm{S}$ \\
\hline \multirow{2}{*}{ Penicols } & Chloramphenicol & $\mathrm{R}$ & $\mathrm{R}$ & $\mathrm{R}$ & $\mathrm{S}$ \\
\hline & Florfenicol & $\mathrm{S}$ & $\mathrm{S}$ & $\mathrm{S}$ & $\mathrm{S}$ \\
\hline Polymyxins & Colistin & $\mathrm{S}$ & $\mathrm{S}$ & $\mathrm{S}$ & $\mathrm{S}$ \\
\hline Quinolone & Nalidixic acid & $\mathrm{R}$ & $\mathrm{R}$ & $\mathrm{R}$ & $\mathrm{S}$ \\
\hline Tetracyclines & Tetracycline & $\mathrm{S}$ & $\mathrm{S}$ & $\mathrm{S}$ & $\mathrm{S}$ \\
\hline
\end{tabular}

${ }^{1)}$ Egg 1, 3: S. Enteritidis isolated from egg shell

${ }^{2)} \mathrm{Egg}$ 2: $S$. Enteritidis isolated from egg content

${ }^{3)}$ S: Sensitivity

${ }^{4)} \mathrm{R}$ : Resistance

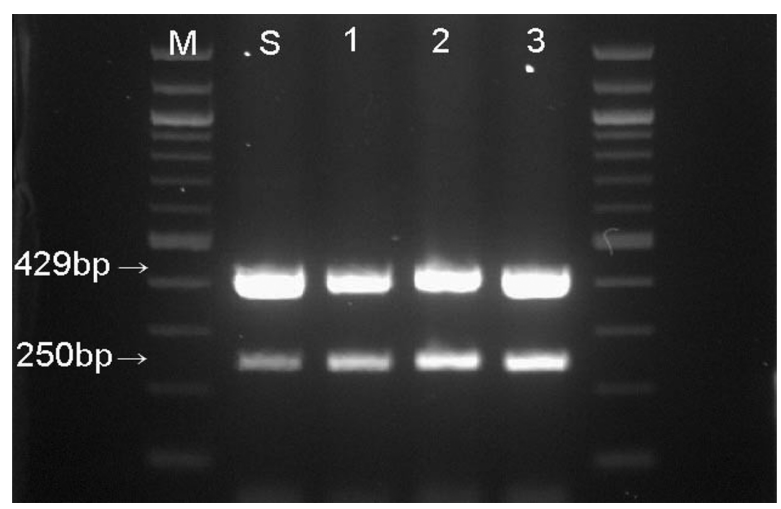

Fig. 1. Detection of Salmonella isolates from eggs by PCR with two primer sets: ST11-ST15 (429 bp) and S1-S4 (250 bp). Lane 1: $S$. Enteritidis ATCC13076; Lanes 2-4: $S$. Enteritidis $(1,3: S$. Enteritidis isolated from egg shell; $2: S$. Enteritidis isolated from egg content), respectively.

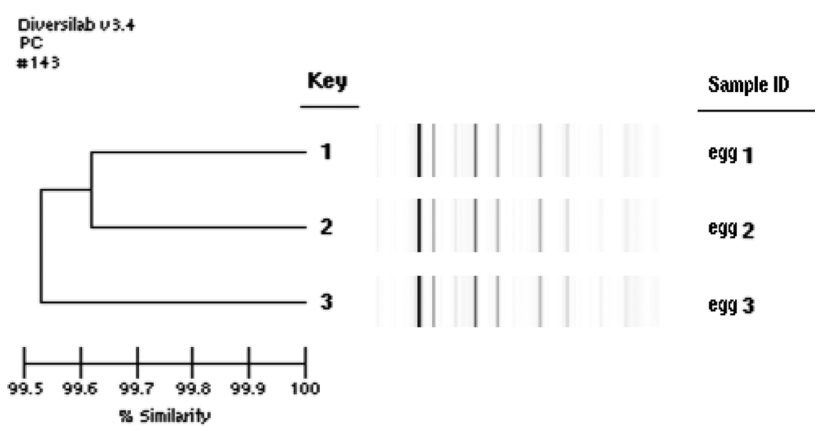

Fig. 2. Rep-PCR generated dendrogram for three $S$. Enteritidis isolates (Egg 1, 3: $S$. Enteritidis isolated from egg shells, Egg 2: $S$. Enteritidis isolated from egg contents)

and egg contents in the United States, United Kingdom, and other countries (Baker et al., 1980; Cowden et al., 
1989; Coyle et al., 1988; Henzler et al., 1998; St. Louis et al., 1988). The $0.66 \%$ of eggs imported into Albania from European countries such as Bulgaria, Italia, Greece, and Turkey were reported to be infected with $S$. Enteritidis (Altin et al., 1999).

In addition, it has been reported that Salmonella present on the egg shell surface enters the egg through stomas or cracks (Cho, 2011; Henzler et al., 1994; Jang et al., 1999). As evident from the test results conducted in the present study, bacteria were isolated from both egg contents and egg shells, identical results were obtained from antibiotic resistance tests, and the isolates showed more than $99 \%$ homology. Therefore, it is possible that bacteria present on the egg shell surface may have entered the egg through stomas and contaminated the egg contents. Hence, it is very important to wash and disinfect eggs before distribution to ensure the safety of consumers from eggs.

$S$. Enteritidis is responsible for serious food poisoning through consumption of eggs. Our study reports the first known isolation of this bacterium from domestically distributed eggs at grocery stores in Korea and it is important in the context of public health and also demonstrates the necessity for preventing and controlling the spread of pathogens in future.

\section{Acknowledgements}

This study was conducted as a part of research in the Veterinary Technology Development Research Project of the Animal, Plant and Fisheries Quarantine and Inspection Agency for the evaluation and improvement of microbiological hygiene for domestically distributed egg products (Assignment Code: B-FS03-2011-12-01).

\section{References}

1. Altin, T., Bizena, B., Kapllan, S., and Elvira, B. (1999) Occurrence of Salmonella spp. in imported eggs into Albania. Int. J. Food Microbiol. 49, 169-171.

2. Amedo, A., Bellido, J. B., Pac, M. R., Criado, J., Usera, M. A., Mesanza, I., Gonzales, F., Perez, R., and Cortes, J. M. (1998) Epidemic outbreaks of salmonellosis caused by eating eggs. Enferm. Infecc. Microbiol. Clin. 16, 408-412.

3. Bacteriological Analytical Manual (BAM, U.S. food and drug adminstration).

4. Baker, R. C., Golf, J. P., and Timoney, J. P. (1980) Prevalence of Salmonella on eggs from poultry farms in New York State. Poult. Sci. 59, 289-292.

5. Cho, J. K., Kang, M. S., and Kim, K. S. (2011) Serotypes, antimicrobial resistance of Salmonella spp. and plasmid profiles, phage types, PFGE of $S$. Enteritidis and $S$. Typhimurium iso- lated from ducks in Daegu-Gyeongbuk province. Korean $J$. Vet. Serv. 34, 217-226.

6. Choi, W. Z., Jung, J. H., Won, H. K., Kang, Z. W., and Hahn, T. W. (2008) Serotypes and genotypes of Salmonella isolates from slaughtered pigs. Korean J. Vet. Serv. 31, 1-16.

7. Chun, M. S. and Hong, S. H. (2009) Identification of microorganisms from eggs in hypermarket in the Northern Gyeonggi area. Korean J. Food Nutr. 22, 394-401.

8. CLSI (Clinical Laboratory and Standards Institute). (2012) Performance standards for antimicrobial susceptibility testing: Twenty-second informational supplement. M100-S22.

9. Codex (1976) Code of Hygienic Practice for Eggs and Egg products (CAC/RCP 12-1976).

10. Cowden, J. M., Chisholm, D., O'Mahony, M., Lynch, D., Mawer, S. L., Spain, G. E., Ward, L., and Rowe, B. (1989) Two outbreaks of Salmonella Enteritidis PT4 infection associated with the consumption of fresh shell egg products. Epidemiol. Infect. 103, 47-52.

11. Coyle, E. F., Ribeiro, C. D., Howard, A. J., Palmer, S. R., Jones, H. I., Ward, L., and Rowe, B. (1988) Salmonella Enteritidis PT4 infection: Association with hens' eggs. Lancet 2, 12951297.

12. Duguid, J. P. and North, R. A. E. (1991) Egg and Salmonella food poisoning: an evaluation. J. Med. Microbiol. 34, 65-67.

13. Ewing, W. H. (1986) Antigenic Schema for Salmonella . In: Edwards and Ewing's Identification of Enterobacteriaceae, 4th Ed. Elsevier Science Publishing Co. Inc., New York, pp. 247-318.

14. FDA (Food and Drug Administration). (2000) Prevention of Salmonella Enteritidis in Shell Eggs During Production, Storage, and Transportation (FDA-2000-N-0190).

15. Henzler, D. J., Kradel, D. C., and Sischo, W. M. (1998) Management and environmental risk factors for Salmonella enteritidis contamination of eggs. Am. J. Vet. Res. 59, 824-829.

16. Henzler, D. J., Ebel, E., and Sanders, J. (1994) Salmonella Enteritidis in eggs from commercial chicken layer flocks implicated in human outbreak. Avian Dis. 38, 37-43.

17. Humphrey, T. J., Greenwood, M., Gilbert, R. J., Rowe, B., Chapman, P. A. (1989) The survival of Salmonellas in shell eggs cooked under simulated domestic conditions. Epiderm. Infect. 103, 35-45.

18. Jang, K. I., Park, J. H., and Kim, K. Y. (1999) Studies on Salmonella Enteritidis contamination in chicken egg using confocal scanning laser microscopy. Korean J. Food Sci. Technol. 31, 771-777.

19. Jones, F. T., Rives, D. V., and Carey, J. B. (1995) Salmonella contamination in commercial eggs and an egg production facility. Poultry Sci. 74, 753-757.

20. Lee, H. W., Hong, C. H., and Jung, B. Y. (2007) Characteristics of Salmonella spp. isolated from poultry carcasses. Korean J. Vet. Serv. 30, 339-351.

21. Lee, S. M., Kim, K. H., Lee, J. G., Park, E. J., Lee, S. W., and Hong, C. H. (2002) Hygienic quality of eggs in the department food stores in the Incheon Metropolitan area. J. Fd. Hyg. Safety 17, 129-136.

22. Lin, F. Y., Morris, J. R., Trump, D., Tilghman, D., Wood, P. K., Jackman, N., Israel, E., and Libonati, J. P. (1988) Investi- 
gation of an outbreak of Salmonella Enteritidis gastroenteritis associated with consumption of eggs in a restaurant chain in Maryland. Am. J. Epidemiol. 128, 839-844.

23. MAFRA (Ministry of Agriculture, Food and Rural Affairs). (2009) Microbiological and chemical residual inspection on shell egg (MiFAFF Notice 2009-169).

24. QIA (Animal and Plant Quarantine Agency). (2012) Standards for processing and ingredients specifications of livestock products (QIA notice 2012-162).

25. Rowe, B. (1989) Salmonella Enteritidis: The program nationally and internationally. In: proc. Xth. Int. Symp. World Assoc. Vet Food Hyg., Stockholm. 326.

26. Soumet, C., Ermel, G., Rose, N., Drouin, P., Salvat, G., and Colin, P. (1999) Evaluation of a Multiplex PCR assay for simultaneous identification of Salmonella spp., Salmonella Enteritidis and Salmonella typhimurium from environmental swabs of poultry house. Lett. Appl. Microbiol. 28, 113-117.

27. St. Louis, M. E., Morse, D. L., Potter, M. E., DeMelfi, T. M., Guzewich, J. J., Tauxe, R. V., and Blake, P. A. (1988) The emergence of grade A eggs as a major source of Salmonella Enteritidis infections. J. Am. Med. Assoc. 259, 2103-2107.

28. Watkins B. A. (1995) The nutritive value of the egg. In: Egg science and technology Stadelman, W. J., and Cotterill, O. J. The Haworth press. 4th, pp. 177-194.

29. Wilson, I. G., Heaney, J. C., and Powell, G. G. (1998) Salmonella in raw shell eggs in Northern Ireland. Commun. Dis. Public Health. 1, 156-160.

30. Woo, Y. K. (2005) Microbial hygienic status of poultry meats and eggs collected at the public markets in Seoul and Kyunggi regions in 1996. Korean J. Microbiol. 41, 38-46.

(Received 2013.1.4/Revised 2013.3.29/Accepted 2013.4.9) 